\title{
Correction to: Three-dimensional reconstruction of the distribution of elemental tags in single cells using laser ablation ICP-mass spectrometry via registration approaches
}

\author{
Stijn J. M. Van Malderen ${ }^{1}$ - Thibaut Van Acker ${ }^{1}$ Brecht Laforce ${ }^{2}$. Michiel De Bruyne ${ }^{3,4} \cdot$ Riet de Rycke $^{3,4}$. \\ Tomoko Asaoka ${ }^{5}$. Laszlo Vincze ${ }^{2} \cdot$ Frank Vanhaecke $^{1}$
}

Received: 8 March 2019 / Accepted: 8 March 2019 / Published online: 28 March 2019

(C) Springer-Verlag GmbH Germany, part of Springer Nature 2019

\section{Correction to: Anal Bioanal Chem https://doi.org/10.1007/s00216-019-01677-6}

The authors would like to call the reader's attention to the fact that unfortunately the originally provided affiliation for Dr. Tomoko Asaoka was not correct. The correct affiliation is:

Department of Internal Medicine and Pediatrics and VIB Center for Inflammation Research, Ghent University, Technologiepark 71, 9052 Ghent, Belgium

Publisher's note Springer Nature remains neutral with regard to jurisdictional claims in published maps and institutional affiliations.
Published in the topical collection Young Investigators in (Bio-)Analytical Chemistry with guest editors Erin Baker, Kerstin Leopold, Francesco Ricci, and Wei Wang.

The online version of the original article can be found at https://oi.org/10. 1007/s00216-019-01677-6

Frank Vanhaecke

Frank.Vanhaecke@UGent.be

1 Atomic \& Mass Spectrometry (A\&MS) research unit, Department of Chemistry, Ghent University, Campus Sterre, Krijgslaan 281 - S12, 9000 Ghent, Belgium

2 X-ray Microspectroscopy and Imaging (XMI) group, Department of Chemistry, Ghent University, Campus Sterre, Krijgslaan 281 - S12, 9000 Ghent, Belgium
3 Department of Biomedical Molecular Biology and VIB Center for Inflammation Research, Ghent University, Technologiepark 71, 9052 Ghent, Belgium

4 Ghent University Expertise Centre for Transmission Electron Microscopy and VIB BioImaging Core, Ghent University, Technologiepark 71, 9052 Ghent, Belgium

5 Department of Internal Medicine and Pediatrics and VIB Center for Inflammation Research, Ghent University, Technologiepark 71, 9052 Ghent, Belgium 